\title{
Uses, Users, and Use Environments of Television Maps
}

\author{
James R. Carter \\ Geography/Geology Department \\ Illlinois State University \\ Normal, IL 61790-4400
}

INTRODUCTION

"Television weather presentations with the accompanying maps are part of American culture, as well as a business."
Weather maps have been part of our television environment for more than half a century and, as such, have become part of our culture. Weather maps are seen in a unique environment where users know when and where to tune in to see maps that they have become comfortable viewing. It is argued that these weather maps are good examples of animated cartography and complementarity in cartography. Weather programming on U.S. television is grouped into four types: local, national, all-news, and all-weather. Although it can be argued that more people see weather maps on television than any other type of map, these weather presentations are designed and produced by a community which includes few if any cartographers. The weather maps are used in many different ways, including a general education of the public and entertainment comparable to watching a sporting event. A typology of weather map users is developed based on what users want to get from the maps.

$\mathrm{W}$ eather maps presented on television in the United States are arguably the maps seen by the greatest number of people. The weathercasters with their maps are portrayed in jokes and cartoons and are written into television programs and movies. Television weather presentations with the accompanying maps are part of American culture, as well as a business. Like other aspects of American culture, the television weather culture seems to be spreading around the world. In 1997, Scharfe organized and hosted the first international conference on Mass Media Maps in Berlin. A significant part of the program was devoted to Weather Presentations in Mass Media with most attention given to weather maps on television. Papers in the proceedings of that conference reported on television weather maps and mapping in the Czech Republic, France, Germany, and the United States (Scharfe, 1997). It was surprising to find The Weather Channel (Der Wetter Canal) on Berlin television. The channel is available in many countries, as are other commercial weather presentations. The nature of television weather programming around the world is not dissimilar to that found on commercial television in the U.S.

In the recent volume Ten Geographic Ideas That Changed the World, Monmonier (1997) argues that the weather map is one such idea because it has done much to shape our lives, although it is taken for granted. "Snapshot views of the state of weather are so readily available, we easily forget they are one of the great inventions of modern geography." (Monmonier $1997,40)$ While Monmonier gives recognition to the contributions of the many weather maps in our midst, Muehrcke (1996) asserts that "...less than half of the adult population in the United States can perform even the most basic tasks related to using maps." If Muehrcke is right, then many television viewers get little from the weather maps. Yet, television weather rates very high in viewership among all of the news programs. Does this mean that all of the dynamic and colorful maps mean little to the public, or that weather maps fall outside the purview of maps considered by Muehrcke? This paper does not answer these questions specifically, but it attempts to provide some structure for determining how weather maps on television are used. 
There are many dimensions to the study of map use. One dimension focuses on the users who bring varied experiences, skill levels, interests and motivations to the task of viewing the maps. Non-users should be recognized in this mix because they are people who for one reason or another choose not to make use of the weather maps that are displayed all around them. Another dimension in the study of map use is the viewing environment; the ways in which viewers can and will interact with the maps. In the case of television maps, that environment is quite constrained. Still another dimension of map use is the community that produces and presents the maps, thereby setting de facto standards as to what is shown and thereby determining or limiting how the maps can be used. And finally, there are the many different wavs maps are used by all of the people operating within this constrained environment. These many dimensions of map use apply to all types of maps and mapping. Weather maps on television are a very specialized form of map presentation, but within this specialized environment there is considerable variation.

The map use environment determines the ways in which the map user can and will be able to interact with the map. Traditionally, maps and map use are discussed in terms of graphics printed on paper and in the hands of the user. With these paper maps, in most cases, the user has great control over the environment in which to use the map. The user can choose when and where to study the map, can linger over the map, can use reading aids, change light levels, make measurements, and draw on the map. Torguson (1997) looks at the dynamic and interactive environments that should come with electronic atlases. In those environments, users are given control over interactive tools to work with maps and explore atlases. By contrast, the viewer of maps on television has no control over the viewing environment. Television viewers see a map appear on the screen only to disappear when replaced with another image. In most news stories, the viewer has little or no warning if a map will be presented, when it is coming, or how long it will be shown. Television viewers can only passively watch maps come and go on the screen

The map-viewing environment of TV weather is distinctly different from the environment of other maps seen on television because, in the weather program, the types of maps and times of presentation are consistent from day to day. The viewer knows when to tune in and has reasonable expectations of the nature and format of the material that will be shown, with new thematic information imposed on familiar map bases. And, there will be that familiar personality sequencing the maps and making interpretations. This unique viewing environment sets the use of television weather maps apart from all other types of map use, whether they are other maps on TV, paper maps, or electronic atlases.

The relatively low resolution of television technology imposes severe limitations on the presentations of map detail. Brown (1993) and Lindgren (1991) give overviews of this technology as it relates to cartographic design and the limitations on the presentation of maps on screen. HDTV, high definition television, should overcome some of the limitations of the current standards, and it will be interesting to see how the nature of television weather maps change in this new environment.

The current low-resolution technology does facilitate the presentation of colorful animated maps with flashing icons, pulsating lines, loops of radar echoes and satellite images of clouds, 3D fly-overs, and morphed fronts and air masses (Carter, 1996). Peterson (1995) emphasizes the power of animation which "...depicts something that would not be evident if the frames were viewed individually" (Peterson 1995, 48). He goes on to note that
"There are many dimensions to the study of map use."

THE TELEVISION VIEWING ENVIRONMENT

"The map-viewing environment of $T V$ weather is distinctly different from the environment of other maps seen on television..."

". . . it will be interesting to see how the nature of television weather maps change in this new enironment. [high definition television]" 
"... there are many examples of cartographic animations right in front of us-on television weather programs."

"... cartographic complementarity is well represented in most television weather presentations, for it is rare that only a single map is used to show the weather."

"Anyone who looks at more than one weather presentation on television in order to get a feeling for what is going on in the atmosphere must be making his or her own mental map ..."

\footnotetext{
"While television weather is map rich, the viewer has no control over how to receive those riches but does know where and when to find them."
}

"...there have been few examples of cartographic animations, due largely to the complexity of their creation, presentation, and cartographer's fixation on the printed map." Carter (1996) responded that there are many examples of cartographic animations right in front of us-on television weather programs. Admittedly, cartographers have not been central to designing and presenting those maps. The fact that these animated maps are not thought of as part of cartography supports Monmonier's contention that weather maps are so readily available that they are easily overlooked.

These animated weather maps contribute to cartographic complementarity, which Monmonier $(1996,77)$ notes "... seeks efficiently informative presentations by minimizing needlessly redundant information as well as by juxtaposing or integrating multiple measurements or themes needed for insightful interpretation." Such cartographic complementarity is well represented in most television weather presentations, for it is rare that only a single map is used to show the weather. Far more common is a collection of maps to show cloud cover, radar echoes, and the synoptic map for the present and a forecast for the near future. And, maps of temperature, dew points, and areas of precipitation add even more information to help the viewer make insightful interpretations. In addition to the maps, the presenter interprets the patterns shown on the map, pointing out where the cold air is coming from, using hands and body motion to emphasize the movement of the flow around a center of low pressure, etc. Such complementarity is also found in the statistics given about the past weather and forecast conditions.

In addition to this complementarity found in any one given weather program, television viewers frequently have the option to switch channels and see how another weathercaster addresses the same subject. Comments from friends and colleagues have indicated that the practice of looking at more than one weather program is common.

Muehrcke $(1996,275)$ argues that much can be gained from doing one's own mapping and creating one's own graphic representations where abstractions must be used. He makes this observation with respect to the growing number who will use computer systems to make their own maps. Anyone who looks at more than one weather presentation on television in order to get a feeling for what is going on in the atmosphere must be making his or her own mental map, i.e., doing the abstraction. The viewer watches a weathercaster interpret the situation and then compares that with another interpretation, and perhaps another. It may be interesting to see one presenter venture a forecast that is different from another, but these differences cannot be discerned unless a mental map of the ones previously seen has been formed. Paper maps can be laid down side by side and systematically compared, feature by feature. With television, mental images from the earlier viewing must be carried for comparison with the later. For many, a set of mental maps are being made as each person watches a presenter work through a set of complementary maps with complementary chatter, body language, and statistics.

The environment of television weather maps is unique among all mapviewing environments in that the viewer gets to select from a variety of colorful, animated presentations of weather with the click of a button. Further, more than a single map is viewed with integrated sequences of maps and complementary information under the control of a presenter who may be very adept at the task of presenting the material. In addition, in many places the viewer has the option to get still other map presentations about the same weather story. While television weather is map rich, the viewer has no control over how to receive those riches but does know where and when to find them. 
In his history of television weathercasting, Henson (1990, 5-6) notes that weather broadcasting was being done in 1940-41, before most people were familiar with the concept of television. World War II interrupted the expansion of television, but it helped to advance the technology of weather forecasting. After the War, many ex-military meteorologists became the new television weather personalities. The news was treated with respect in those early years and weather was considered to be a subset of the news at large. Soon, television weather departed from its radio formats because, as Henson noted,

The visual nature of television demanded 'action' in the form of weather maps and bright, attractive people who could explain them. The frontal theory of weather forecasting was then just 30 years old; weather maps had become a newspaper standby, but the workings of occluded fronts and high pressure ridges were hardly common knowledge. (Henson $1990,6)$

These pioneer weathercasters had to introduce to a large public such concepts as highs, lows and fronts. Using today's terminology, maps are used on television to 'visualize' the spatiotemporal nature of the atmosphere by showing components of weather systems moving across the land.

In 1952, the federal government opened the airwaves, which led to a proliferation of television stations. By the mid-50s, "Most cities with populations over 100,000 had at least two stations competing for viewers ..." (Henson, 1990, 8). In 1982, John Coleman instituted a revolutionary concept by showing maps on television 24 hours per day, seven days per week (Henson, 1990, 99-100). Today, The Weather Channel reaches 69 million subscribers on cable, and versions of it are subscribed to by another 26 million people around the world (Petrozzello, 1997a). With the availability of retransmission consent agreements earlier this decade, LIN Broadcasting has developed local versions of 24 hour weather broadcasting in direct competition with The Weather Channel in select markets (Merli, 1997). Now, some local cable systems are providing AccuWeather weather coverage up to 24 hours per day as a complement to The Weather Channel (Petrozzello, 1997b). In the political climate of 1995, when public television came under attack and devolution of the federal government was popular rhetoric, A.M.Weather was dropped from PBS for a variety of reasons (AM Weather, 1995). This unique 15-minute morning program, with presentations of upper air patterns and a segment for pilots with maps showing visibility ratings, had been a mainstay of public television since 1978 (Henson, 1990, 97).

Currently, the weather presentations on television in the United States fall into four types:

1) Local stations that have a 2-3 minute weather segment in the local news two or more times a day. The focus is on the regional and local weather but most presentations include an overview of the national pattern. The nature and quality of these maps and presentations vary greatly (Figs. 3-14).

2) National networks that have short weather segments accompanying their morning 'news' programs, generally with simplified national maps showing the synoptic pattern and temperatures (Figs. 1 and 2).

3) Full time news channels, such as CNN (Fig. 17), having weather segments presented throughout the broadcast day.

4) The Weather Channel and, in selected areas, Local Weather Service or AccuWeather Local Cable Weather Service that present continuous coverage of weather 24 hours a day, 7 days per week (Figs. 15-16 and 1821).
EVOLLTIONOF THE

TELEVISION WEATHER

ENVIRONMENT

"The visual nature of television demanded 'action' in the form of weather maps and bright, attractive people who could explain them."

"In 1982, John Coleman instituted a revolutionary concept by showing maps on television 24 hours per day, seven days per week."

"Currently, the weather presentations on television in the United States fall into four types:..." 


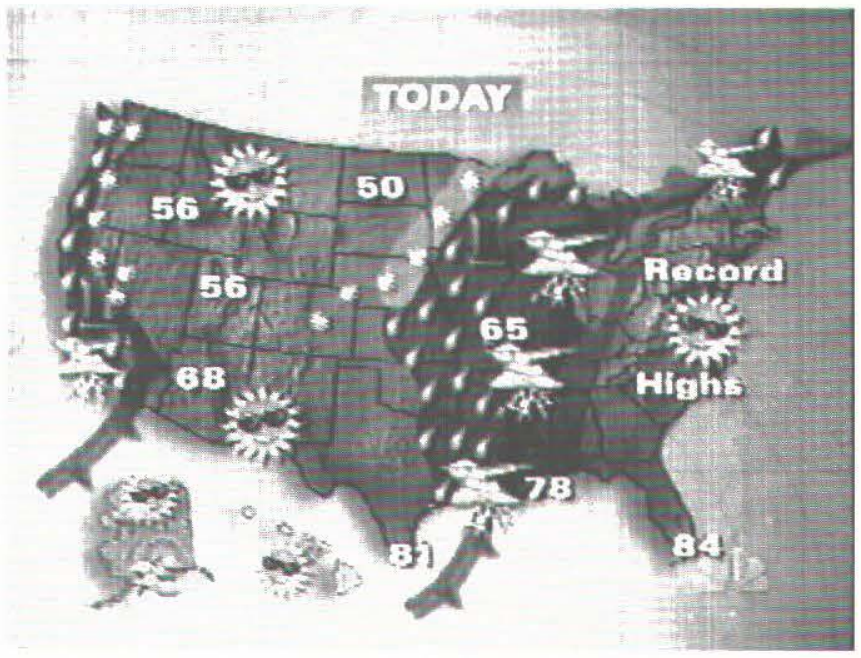

Figure 1. Map from the NBC morning program itith smiling, golden

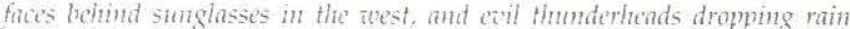
oier the Midzest. This map has everything lut a presenter: numbers, texf. fronts wifh drop shadot's, and insets for Alaska and Hawaii.

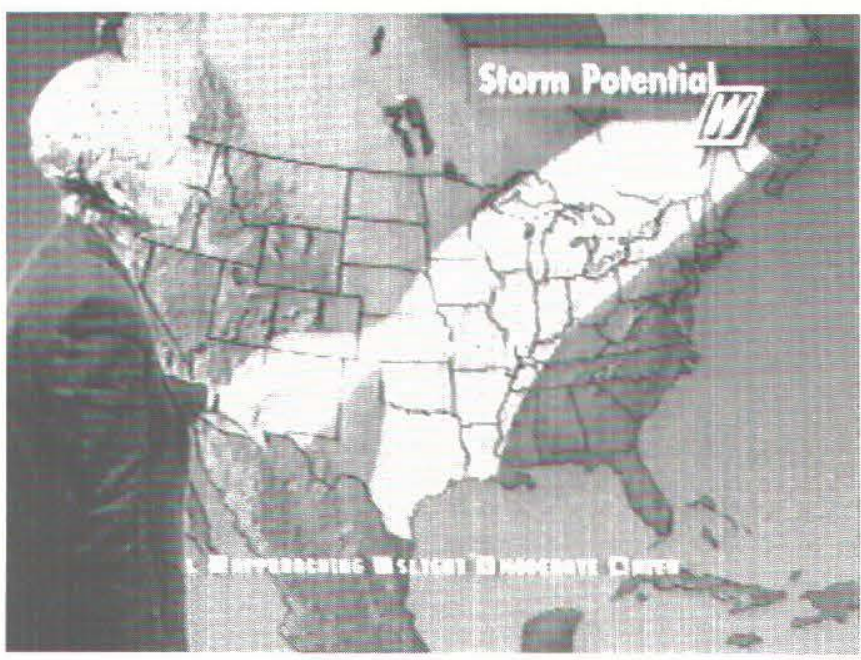

Figure 3.

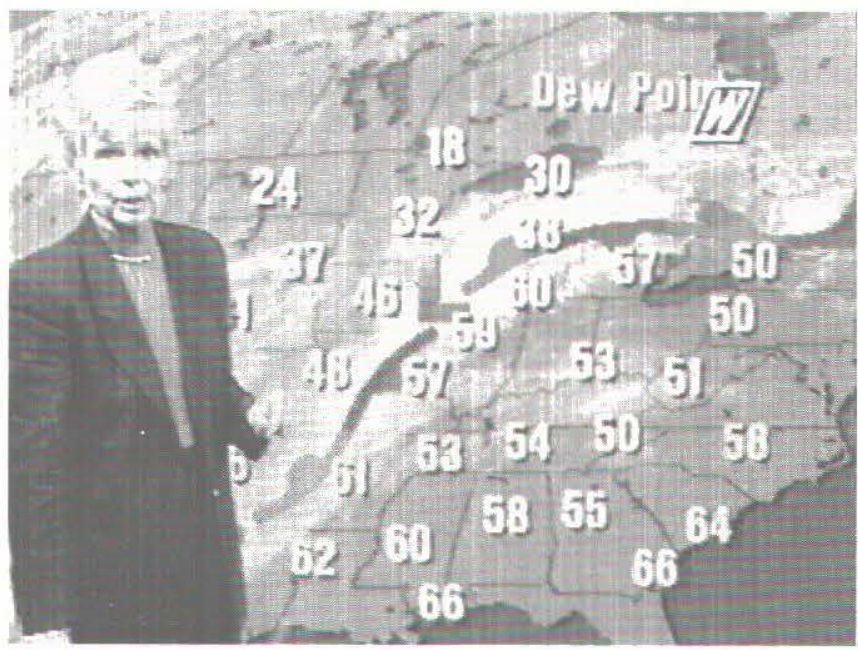

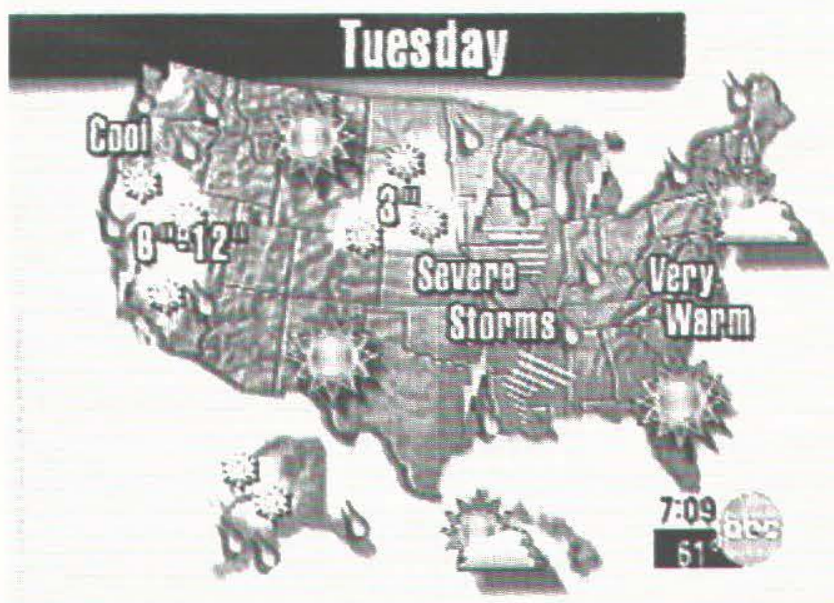

Figure 2. Map from the $A B C$ morning program with bold text and large, colorful icons portraying the weather. This map has no fronts but does have raindrops, snoweflakes, sunbursts, and hatched patterns showing the arens of severe storms. It also includes insets for Alaska and Hawaii. There is no presenter in this image.

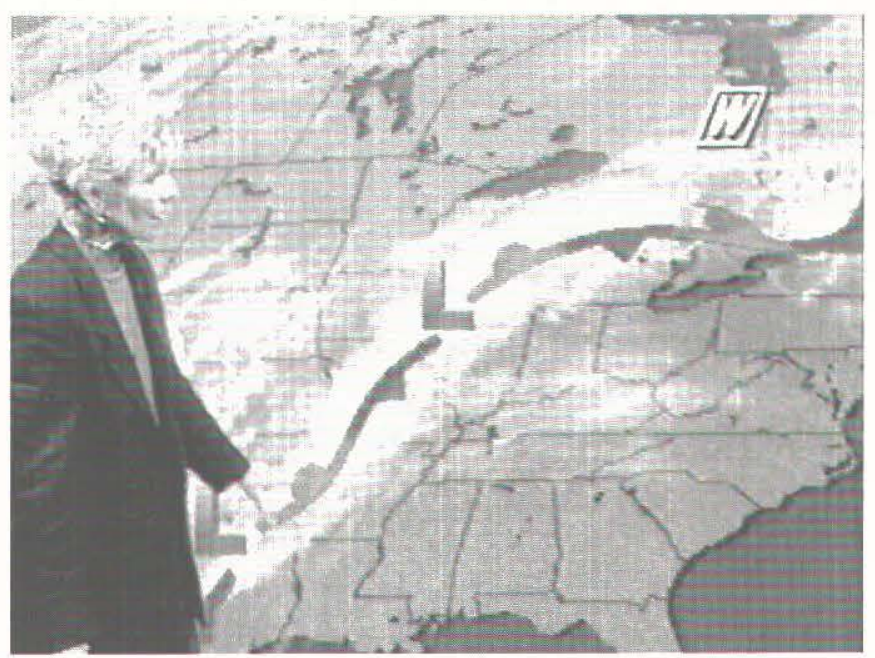

Figure 4

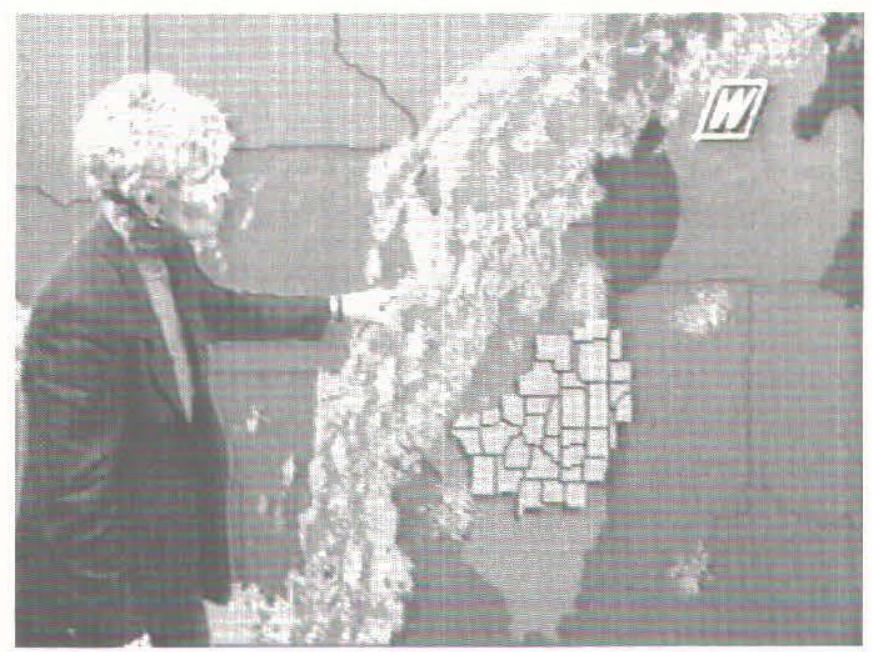

Figure 6 , 


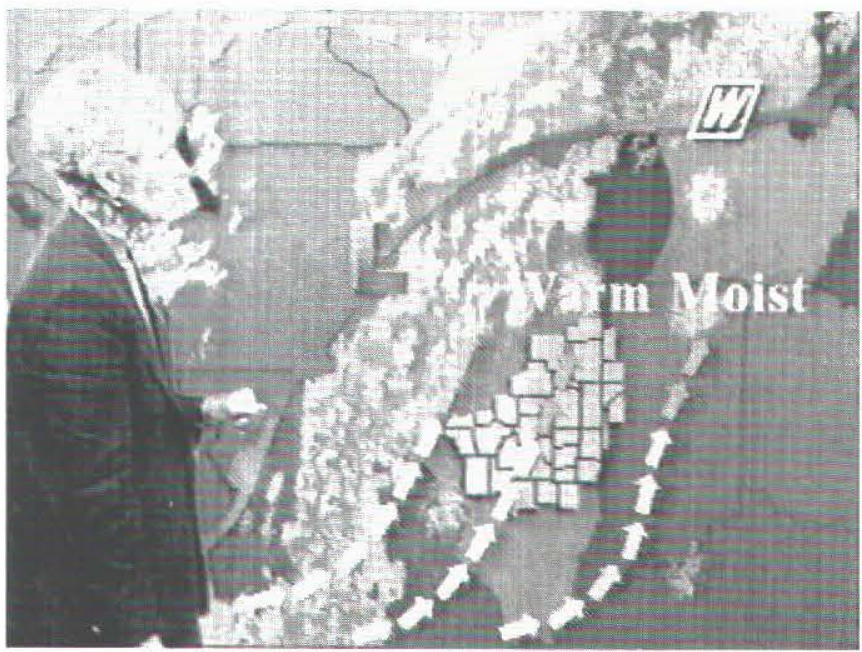

Figure 7.

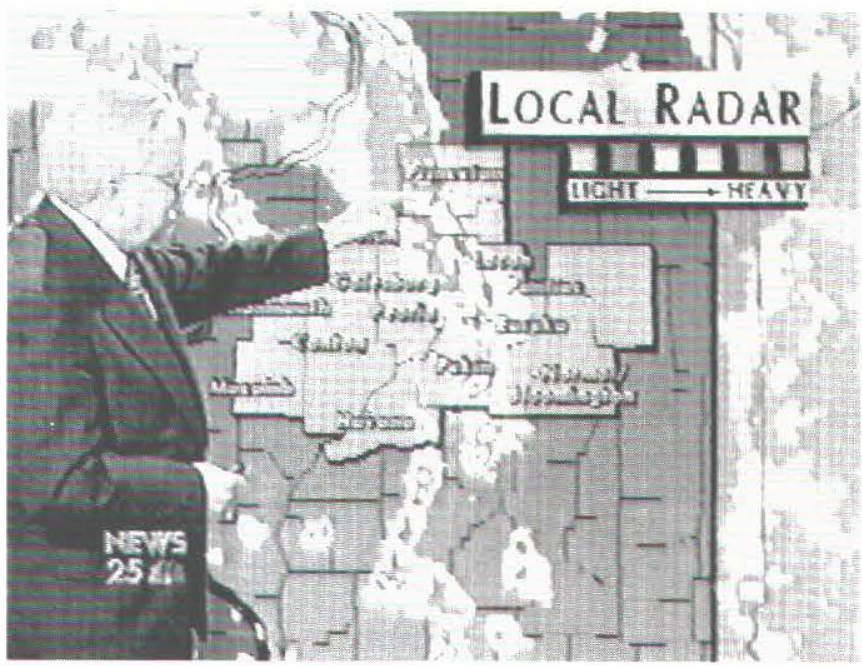

Figure 8. Lee Ranson of WEEK-TV, Perial IL, showe the presentation of ratar on a local progran. This is a relatively large-scale presentation showing considerable detnil in the countes of central llinots. This is a comparatiaty simple presentation of radar imagery.

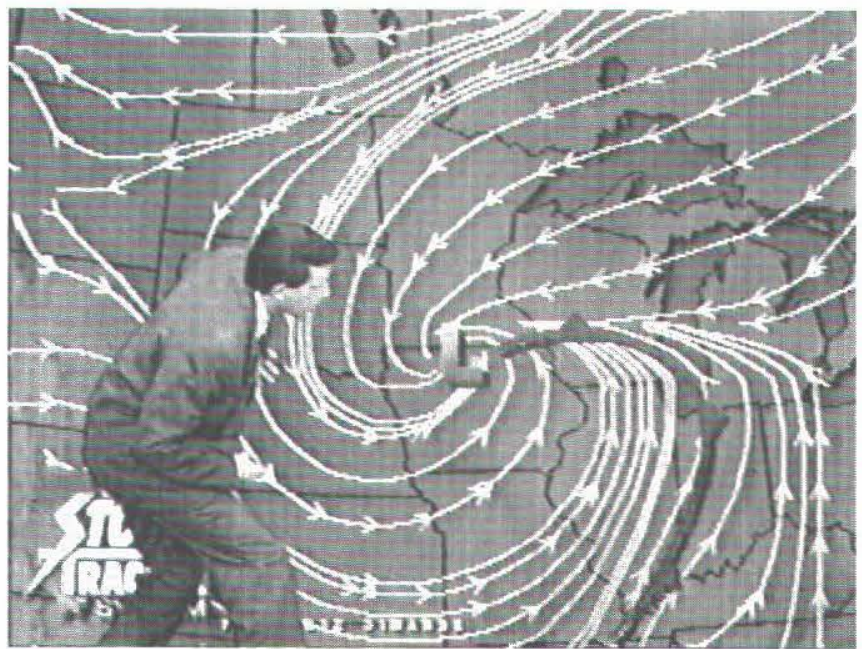

Figures 3-7. A sequence of maps with Judy Frasier, WCIA-TV. Champaign, $I L$, explaining the ways the elements come together to produce this strong extra-tropical cyclone. 3 -shows isolines delimiting color filled zoncs representing storm potential. 4 - is a perspective view of the central part of North America showing a frontal bountary imposed over a map with cloud coere. 5 - is the next in the sequence where dew point temperatures are plotted, using different colors for the high and low walues. 6 - is a loop of radar imagery mowing ower a larger-scale hase map showing the comnties of East Central Illinois in the viewing area. 7 - builds on the previons map with fike addition of the frontal line and sequences of pulsing arrowheads portraing the rotation of air about the Low. There is consiternble difference in the two regional base mans used in this same presenfation.

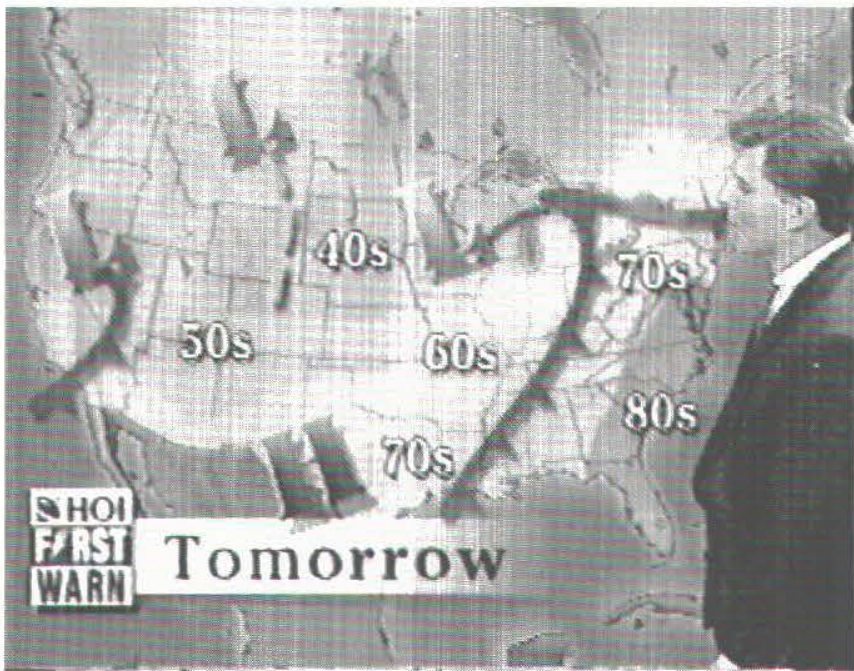

Figure 9. Ric Kearbey of WHOL-TV, Peoria. IL, with a relatively simple map of Nortin America centered on the continental U.S., with large symbols, proiected temperatures for tomorrou, and the station logo Note the bold shadou's underiying the $F$ is, $L$ s and the fronts.

Figure 10. Mike McClellan. WMBD-TV. Peoria, IL, puts his whole hody into the effort to showe how surface streanlines are spiraling into the Lot tentered oter nertiem lowa. Such stremime maps are used occasionally by the more tedmical lincal weathercasters when the symeptic situation protuces a brond. regional pattern that viewers can unterstant. Note the bold station loge in the southuest corner and the dark erdee along the frontal boundiry. 

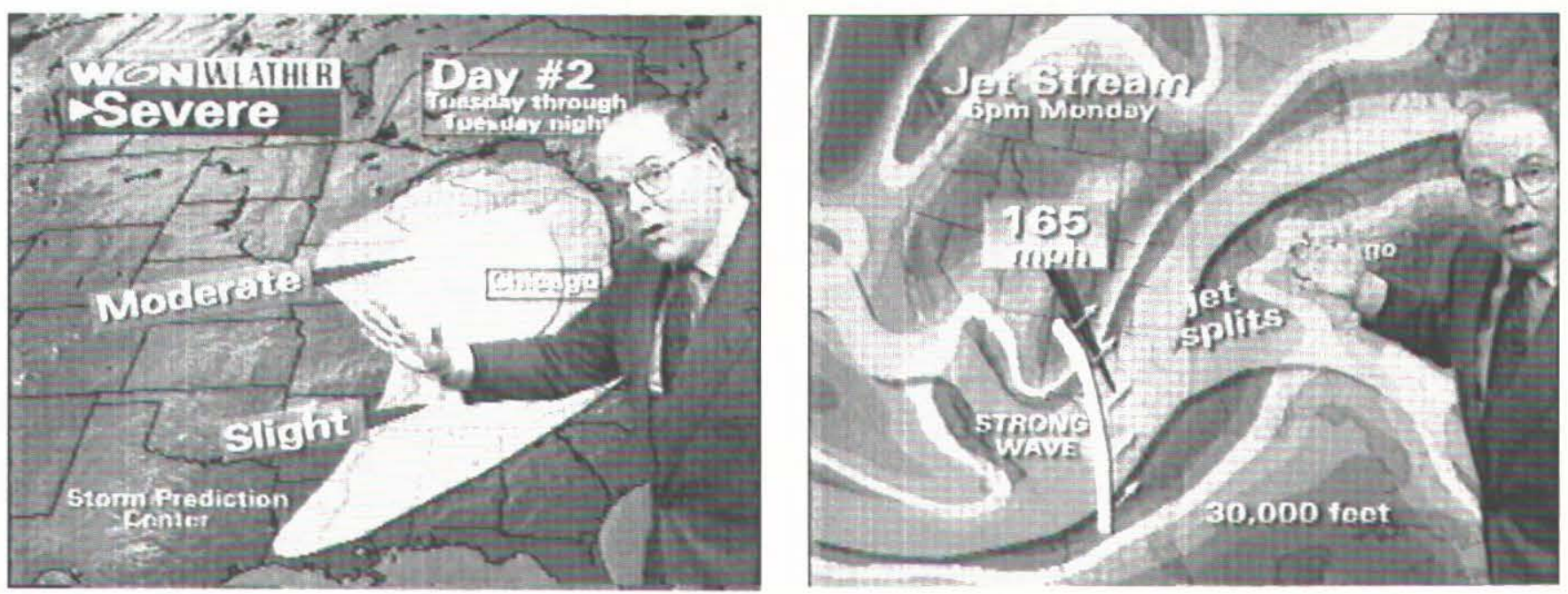

Figure 11

Figure 12.
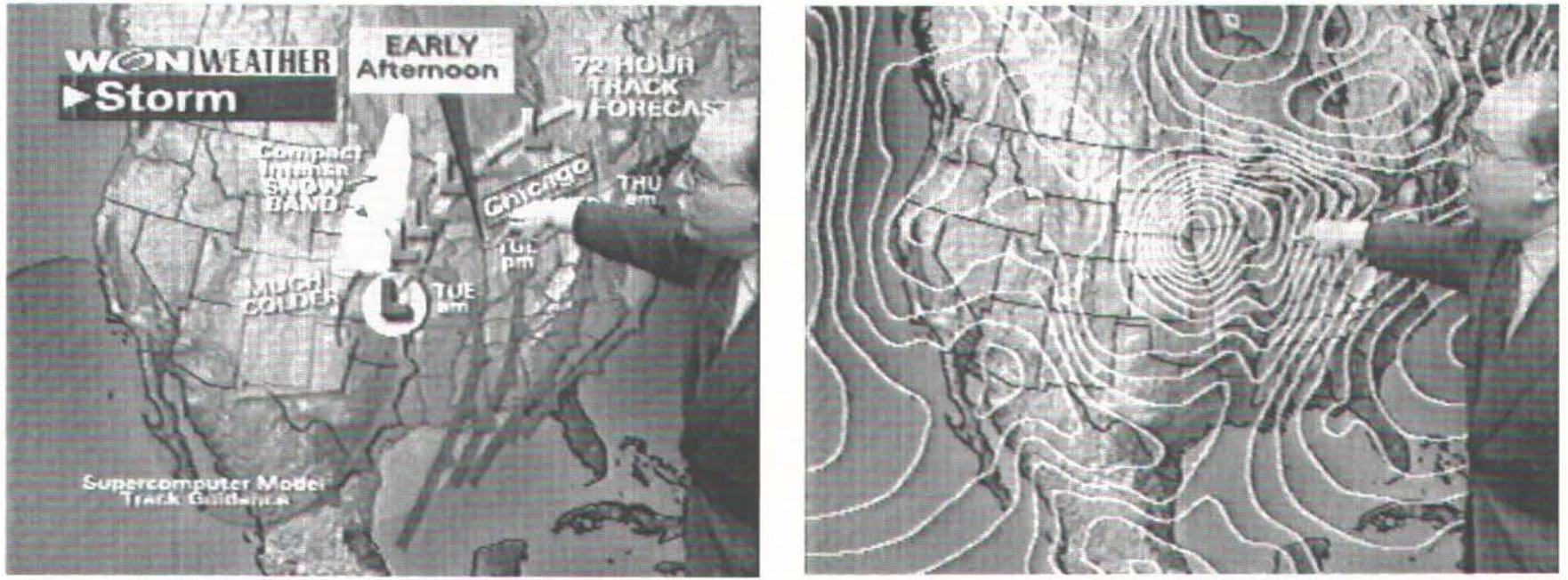

Figure 13

Figure 14

Figures 11-14. Tom Skilling of WGN-TV. the Chicago super station that is available to tens of millions via cable, is known for his challenging graphics. Many meteorologists watch him, although some confess they are not certain what they have seen after his program. In this series, in one map (11) he shows the predicted arens of severe weather. In one box at the top we see the date for which the forecast applies, in another the station logo, and along the bottom is the source of the information. This is a lot to read on a map that may be on the screen less than 5 seconds. The second map (12) employs a fantasia of colors to represent jet streams converging and diverging at 30,000 feet. The firird map (13) shows the current and three proiected positions of fronts and centers of the Lou over the next 72 hours. A considerable amount of text appears on the map, such as Compact Intense SNOW BAND.' At lower left the attribution is Supercomputer Model Track Guidance. The fourth map (14) emplous isobars that, in this case, vividly depict the dienth of the center of Low pressure. Isobars are not used commonly of television aveather maps. Note that all of Skilling's maps extend seamlessly over Camado.

"To be competitive in this diverse mix, weather presenters must have some combination of personal charm, reliable forecasts, and quality graphics."
To be competitive in this diverse mix, weather presenters must have some combination of personal charm, reliable forecasts, and quality graphics. While there have always been weathercasters with strong meteorological experience, for many years the typical weather presentation seemed to be dominated by personalities relying on comedy or sex appeal to attract audiences. Today overt sex appeal is no longer used, but a little levity is still employed by some weather presenters, particularly on the morning programs on the national networks and some local weathercasters. By contrast, the weathercasters on the all-news and continuous weather channels tend to be professional in their interaction with the subject matter and suppress 

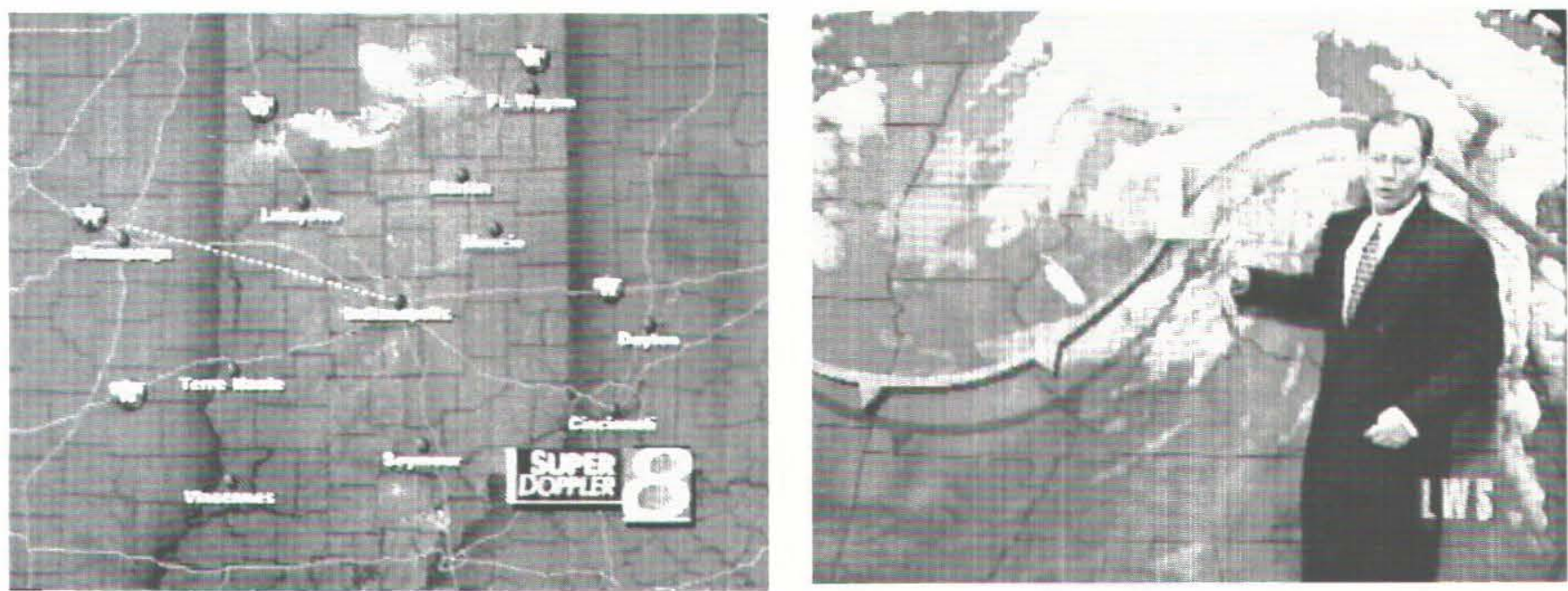

Fisiti 15.

Figure 16

Figares 15-16. LWS in Indianabolis is a 24-hour weather channel tied to channel 8, the local commercial channel. The Super Doppler radar map

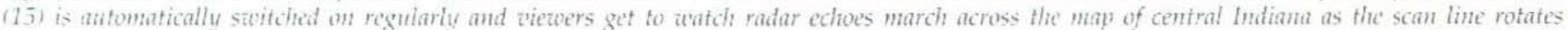
chechise around the central point in Indianapolis. Fig. 16 portrays the weatheraster cxplaining the synoptic patterns an a map aith stylized cloud patterns and frents that rise high orer the land, as indicated by the shadous standing apart from the fronts. Bu definition. fronts on maps show the boundartes of dissimitar air masse's an the earth's surface.

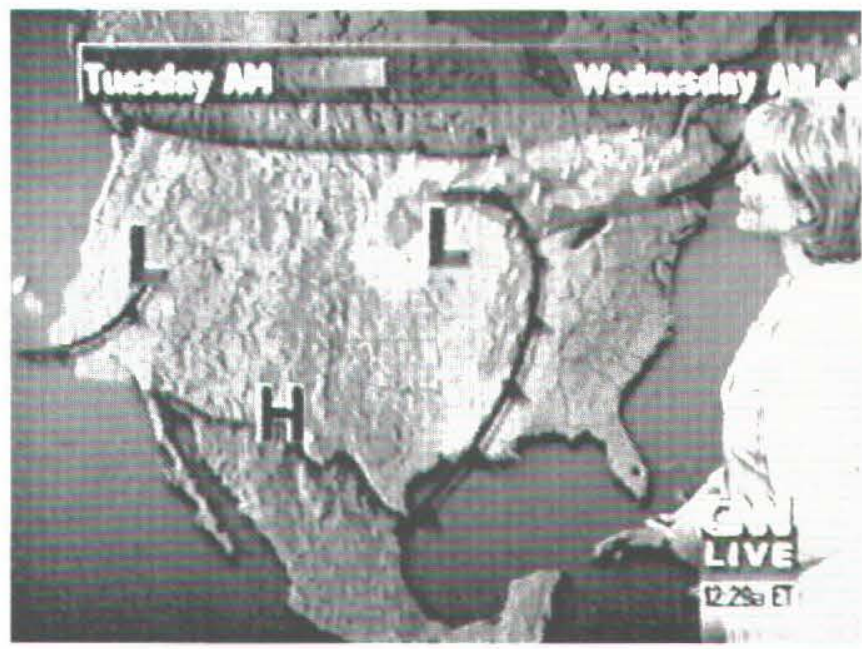

Figure 17. This is an example of the animated weather map series on CNN. As the fronts ghide atross this map, a timer bar slides along the top to show when the map situation is forecast to occar. The precision of the timer bar is fuzzu and it is difficult to focus on the timer while wating the weather patteris move orer the map. The graphics sustem thed to generate these maps was developed by a Norargion farm. CNN has worked dosely with that firm to create this system of mal presentation.

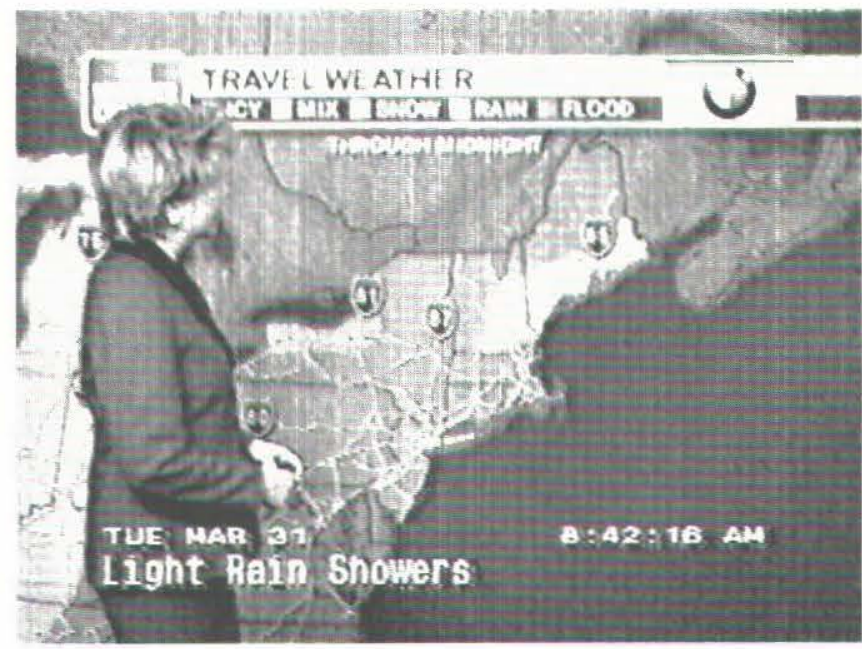

Figure 18. This is but one of many possible choices from The Weather Channel. This is a nen-animated regional Travel Weather map over the northeastern U.S. showing weather only to the national border. To orient ciewers, interstate highways are shown, and a few are labeled. Across the top of the map is the legend, with the map title. The Weather Chamel logo, and an advertising ioge, in this case that of BMW. To satisfy local ziezters, but add complexity. local statistics for central Illinois are overpinted along the botton portion of the image. any hint of comedy. Still, across all of these environments, the weathercasters note that it is important to build rapport with the audience and not appear to be too serious.

Any discussion of the many types of maps on television requires that a sample of those maps be shown. Because the maps on television weather programs are colorful and dynamic, they are not captured or portrayed well as static frames in black and white. Many television weather maps have so little contrast in black and white that they are totally washed out when represented this way. In addition, it should be noted that some maps could
A SAMPLE OF TELEVISION WEATHER MAPS 


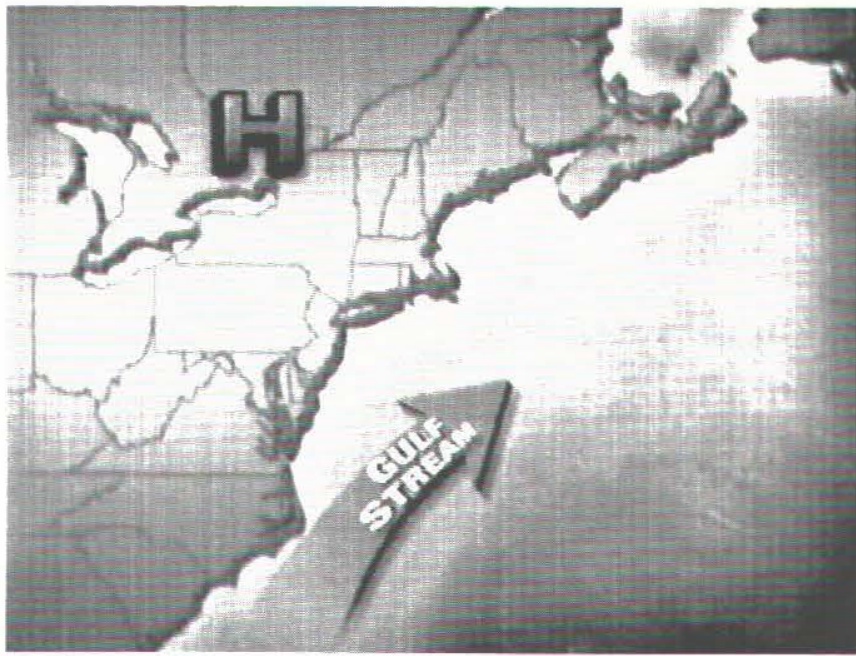

Figure 19.

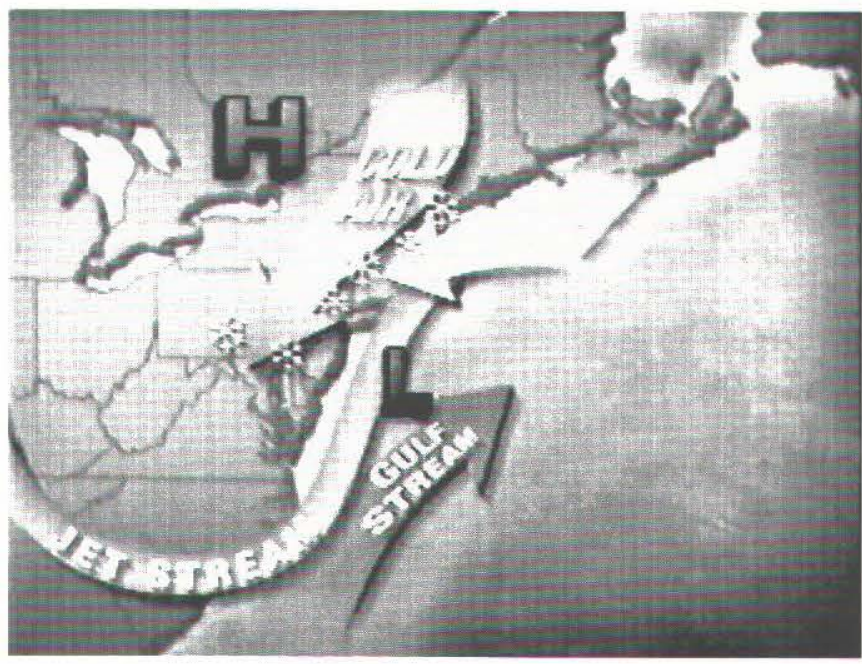

Figure 21.

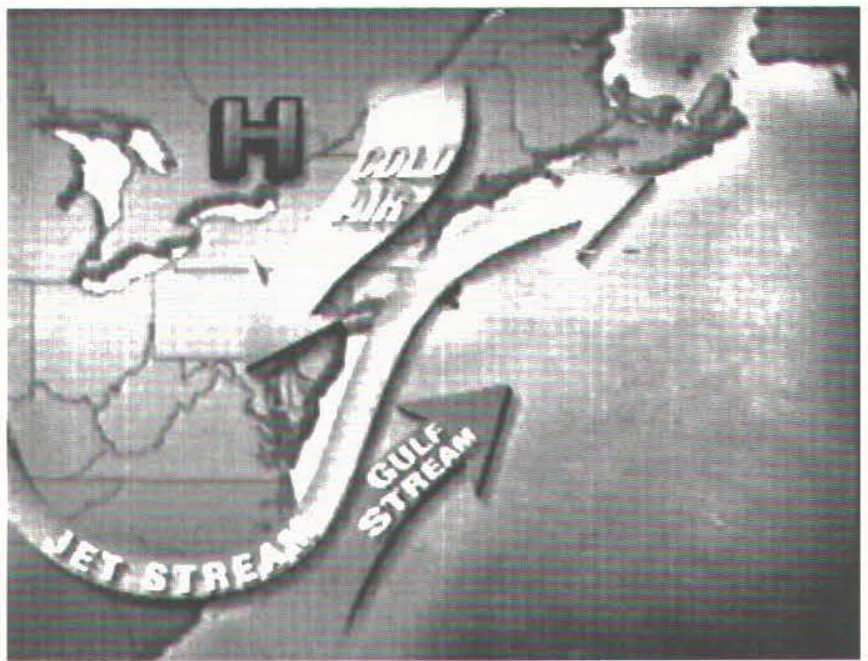

Figure 20

Figures 19-21. This series of three thematic maps are samples from the sequence of seven such maps The Weather Channel used to explain the forces producing the Nor'Easter that swept up the coast in late spring 1997. One map shows the center of the High and the warm Gulf Stream. The flow of Cold Air and the Jet Stream are added to produce the second map. The final map has moisture blowing in off the Atlantic and many snow flakes. Such sequences of simple, straightforward maps are very effective in explaining how particular storm systems form and evolve. Such map sequences are used frequently on The Weather Channel when severe and damaging weather occurs in the U.S.
THE WEATHERCASTING COMMUNITY AND MAPS not be used because the station or channel could not give permission to print certain types of data.

While Americans can see weather maps of the entire world and separate continents on television, the maps shown here are maps of weather in the U.S. Many of these maps are representative of what appears in the Midwest during severe weather. Most of these maps were captured March 30-31, 1998, as a large weather system moved through the Midwest. The weather segments were recorded on a VCR, captured in Adobe Premiere at 640 by 480 resolution, then cut and pasted into SimpleText. The images were then processed in Adobe PhotoShop to scale them and convert them to black and white.

The weather programs on television are the end product of an international system of data collection, evaluation, analysis, modeling, forecasting, and dissemination (Carter, 1988). In extensive interviews with many weathercasters, it became clear that the weather presentations on television are first and foremost part of a business enterprise. The stations and channels make decisions based on the need to capture market share, maintain viewers, and provide a return on investment. Even the dedicated on-air meteorologists, while concerned with getting the right information to 
the public, recognize their need to build audience support. Coaches and consultants are brought in to work with weathercasters to make certain they contribute to the image of the station.

Over the years, many cartographers have suggested informally that they could do a better job of designing maps for television weather presentations. Many weathercasters feel the same way and wish that they had the freedom to implement some changes. Almost without exception, the management and / or the art department choose the design of the base maps and the colors. Sometimes the weathercasters participate in the process. Many of the maps and graphics come from the firms that provide meteorological data, images, and maps to the stations. In contrast, the Weather Channel employs a formal team approach to map design and program organization that integrates representatives from all appropriate departments. They also use focus groups of viewers to guide the teams (Eck, 1997).

Most of the local weathercasters noted that they have almost total freedom to organize and present the weather story, as long as they maintain the image of the station and fit the time constraints. Weathercasters have their preferred set of procedures. One reported that he tries to find a story and then sequence the maps to tell the story, while his colleague tries to present a shop filled with helpful products (maps) from which the viewer can pick.

Although consultants report that the weather segment is the most watched part of the local news, that segment is considered the 'accordion' because it gets squeezed or stretched regularly. Often it is shortened up to $30 \%$ (and sometimes more), only minutes before the presentation goes on. Sealls (1994/95) describes the hectic environment in which the weathercaster prepares and presents maps on television. Based on interviews with weathercasters in different environments, only the full-time weather channels seem to operate with fixed time slots that are not changed moments before going on-air. Preparing maps for a presentation that may be cut significantly affects the choice of maps and map sequences that can be considered.

Weather programming is rated very highly in terms of audience appeal, by all measures. "Weather-or some aspect of weather coverage-is the number-one news draw in 11 of the top 20 TV markets, ...92\% of news viewers say weather is something they 'really want to see covered' in local news, followed by the day's local news ( $89 \%)$, live coverage of breaking news $(89 \%)$ and health news $(75 \%)$ " (Bowser, 1997, 61). This is consistent with what the local weathercasters are told by consultants, i.e., that the weather segment is the most watched part of the news. Henson $(1989,1-2)$ cited earlier studies giving high ratings to television weather presentations. Haddad and Cress (1993) reported that The Weather Channel is the fourth most watched of the many cable channels in the U.S. Stations pay handsomely to get ratings, but detailed television station ratings are proprietary. Although access to data is limited, there is no doubt that weather on television has a very large audience.

In general, weathercasters think of themselves as professionals and take pride in the programs they put together. Many have had formal training in meteorology and have degrees or concentrations in television meteorology. In addition to a number of good academic programs in meteorology, there are graduate programs emphasizing television weathercasting, some of which are predominantly correspondence training for those already working on-air (Henson, 1990, 19-20). In many of the schools there is at least one course where students make presentations and then receive criticisms from fellow students, as at Pennsylvania State University (Mirsky, 1996). Beyond the academic programs, the American Meteorological Society
"... cartographers have suggested informally that they could do a better job of designing maps for television weather presentations. Many weathercasters feel the same way..."

"Preparing maps for a presentation that may be cut significantly affects the choice of maps and map sequences that can be considered."

". . . there is no doubt that weather on television has a very large andience." 
"... it appears that academically trained cartographers have not been able to penetrate the world of television weather mapping."

". . Brezver suggests that television weather has had some impact on academic cartography."

"It may be anticipated that the convergence of HDTV and quality, large-scale digital databases, in combination with the powerful computer graphics systems used for weather mapping, will lead to some interesting applications of maps on television."
(1997) and the National Weather Association (1997) have formal programs to certify on-air weathercasters. Annual meetings of both organizations include seminars and workshops designed to give weathercasters pointers and guidance on content, preparation, and presentations. Also, the weathercasters now have a place on the Web to share interests and concerns (Loffman, 1997a).

Based on many interviews with people in the television industry and cartographers, it appears that academically trained cartographers have not been able to penetrate the world of television weather mapping. It is interesting to speculate why this is the case. Foremost, no one has seen the need to employ academic cartographers to improve the maps that go on-air. Stations do employ designers to build local and regional base-maps and improve the look of maps they use on air. Weathercasters praised one such consultant, Valerie Jones, for helping them come up with better maps. She received a degree in meteorology and worked on-air for a few years, then worked for one of the service providers as a trainer in support of on-air weathercasters before going on her own as a consultant (Jones, 1998). Jones has always been interested in maps and traces some of that interest to a great grandfather who was a cartographer. One can assume her progressive experience within the industry positions her to provide the cartographic link to stations that would want such a connection. That experience gives her knowledge of weather mapping, the technology of the television mapping systems, and the design constraints of the television display. The academic cartographic literature has little to say about any of these subjects.

On the other hand, Brewer (1997) suggests that television weather has had some impact on academic cartography. Spectral hues that cartographers once deemed to be inappropriate are now found to be more acceptable because viewers have been exposed to those sequences in television weather presentations. "Spectral hues may now be spontaneously ordered in the public consciousness after continuous exposure to popular spectral graphics on topics such as the ozone hole and weather. The contradiction between the lack of perceived order for spectrum colors and the likelihood that the public is learning this code, through its use on most scientific visualizations that enter the public sphere, is a topic ripe for further research" (Brewer 1997, 217)

There is reason to suggest that academically trained cartographers may find a place in television, but less for their design skills than for knowledge of cartographic databases. One of the people interviewed was hired as a cartographer to help integrate digital geographic databases into some of the more advanced weather mapping systems (Flanagan, 1998). He noted that some of the new databases, especially those related to Doppler radar systems, are very detailed and are being used for maps in the news in addition to weather presentations. In another conversation, a manager inquired about where to get cartographic databases that would permit the rapid production of maps that could be used in emergency situations. Additionally, another person stated that many commercial mapping organizations are discussing ways to become more involved in the television news industry. It may be anticipated that the convergence of HDTV and quality, large-scale digital databases, in combination with the powerful computer graphics systems used for weather mapping, will lead to some interesting applications of maps on television. These maps will owe a legacy to the television weather map and the audiences that have learned to use them.

Weathercasting is a map-rich activity and, therefore, as forecast information is disseminated, maps will be employed. The nature of those maps and the ways they are used in presentations on television reflect the combined 
efforts of the television weathercasting community made up of forecast meteorologists, service providers, television management, consultants, and $T V$ weather presenters. Academic cartographers do not seem to be part of this community. This absence of cartographers should not be a surprise, for as Muehrcke $(1996,272)$ notes: "Most maps are made by graphic artists and others not formally educated as cartographers." Television weather mapping fits the norm.

This paper is based on many years of systematically viewing television weather broadcasts, observing the reactions of many friends and colleagues, interviewing weathercasters, reading anecdotal comments in the popular press, and delving into a fairly limited professional literature. The collection of uses discussed here represents perhaps only a small part of the many ways people use the maps in television weather presentations in the U.S., but it is a start in examining the use of weather maps on television.

Fair Weather / Foul Weather Viewing - Fair weather viewers should be expected to have a different agenda than when the weather poses a potential danger. When a hurricane is bearing down on the area or severe storms with the potential for tornadoes is present, or a blizzard is on its way, people take a heightened interest in the weather. For those in the path of potential danger, these weathercasts have immediate relevancy. Sometimes the concern will be watching for 'official warnings' and reacting to specific instructions. The U.S. National Weather Service uses such television and radio weathercasting to disseminate warnings and advisories in a government / private partnership (World Meteorological Organization, 1996).

In other situations, the potential for danger can be more personalized. As an example, when working at home at a computer and electrical storms are likely, it is wise to monitor the weather on TV for progress of storm cells moving through the local area. Knowing where your residence is on the local map base used to show radar, the computer can be unplugged so as not to suffer damage during the electrical storm that can be estimated to move overhead within a matter of minutes. This immediate feedback can reinforce decisions to watch the radar maps the next time such weather seemsimminent.

Recently, map analysis was employed in deciding to continue a scheduled canoe trip. The day before the scheduled event, it was cold and rainy. The leader deferred on canceling the trip until after she was able to watch the local weather programs as part of the late night news and make her own prediction on when the rain would move out of the area. Because the river was some distance away, the prediction had to be based on pulling together a number of pieces, including the trend of the boundary of the rain zone as portrayed on the radar imagery. At 10:30 PM, in consultation with the other members of the group who watched a variety of weather presentations, the decision was made to cancel the trip.

A significant proportion of the nation seems to tune in to watch severe weather events such as Hurricane Andrew bearing down on southern Florida or the 'blizzard of the century' moving across the Southeastern U.S. and up the East Coast. This can be fascinating for the viewer and the weathercasters relish the fact that they have an audience that is showing heightened interest in their interpretations and forecasts. In many ways, television weather is like sports in that it is highly graphical, the weather events are short-lived, and people can see the results. In near real-time, viewers can watch weather systems evolve as the forecasts are revised. Like sports, people spend hours watching storms play out on maps as experts give commentary. With radar and satellite image loops, there are even instant replays.

\section{USES OF MAPS IN TELEVISION WEATHERCASTING}

"Fair weather viewers should be expected to have a different agenda than when the weather poses a potential danger."

"This immediate feedback can reinforce decisions to watch the radar maps the next time such weather seems imminent."

\author{
"In many ways, television \\ weather is like sports in that it is \\ highly graphical, the weather \\ events are short-lived, and \\ people can see the results."
}


"These competing services employ different forms of radar presentations to monitor the weather."

"The 'School Day Forecast' on the Weather Channel has a similar function in telling parents how to dress their children for school. On that map they use icons such as coats, sweaters, and umbrellas."

"The World Wide Web has many sources of maps that should satisfy pilots, so it is unlikely that any television system will take on the presentation of weather information targeted directly at pilots."
In 1994, the Local Weather Station, or LWS, was brought online in selected market areas to compete with The Weather Channel. Thedwell (1996) noted LWS would "give 90\% local and 10\% national versus The Weather Channel which is the opposite." In practice, those stated proportions are greatly exaggerated. In Indianapolis, IN, The Weather Channel and Local Weather Service occupy neighboring positions on the dial at the high end of the cable service. These competing services employ different forms of radar presentations to monitor the weather. On LWS, the presentation is real-time and continuous and the viewer can watch the storm migrate across the map of central Indiana (Fig. 15). But to appreciate the motion, one must fix on reference points on the map and observe the motion relative to those points. Every ten minutes, The Weather Channel shows a loop of radar echoes over the past three hours. Viewers can watch these loops to see trends in motion across the map. These two dynamic map presentations complement each other and those who can toggle between neighboring channels can watch severe weather march across the map.

Many weather segments are targeted at the traveler (Fig. 18). This is particularly true before major holidays when many people travel, or when snow and ice pose special problems for automobile travel. The Weather Channel, with its national coverage, particularly targets the traveler, including the business traveler who will soon fly to another location. The purpose of this information is to inform the person of the general weather conditions so they might better decide what to wear and to pack. The 'School Day Forecast' on The Weather Channel has a similar function in telling parents how to dress their children for school. On that map they use icons such as coats, sweaters, and umbrellas.

Pilots must contend with weather as they fly into or around specific occurrences. Horne $(1992,93)$ gave emphasis to the role of television weathercasting for pilots when he wrote:

...it's a rare pilot indeed who doesn't consult his television as part of the preflight weather briefing process. For pilots without computers, graphics boards, and customized software, the television has become an indispensable tool—sometimes the only tool—for visualizing current weather and forecast trends, as well as identifying any areas of severe weather.

A.M. Weather with its upper air and visibility maps was the only program with a segment specifically targeted at pilots, but it was dropped in 1995. No television weather program has picked up this coverage, although it was reported that the program would be re-instituted (DR, 1996). The World Wide Web has many sources of maps that should satisfy pilots, so it is unlikely that any television system will take on the presentation of weather information targeted directly at pilots.

Another set of viewers who base decisions on their interpretation of the television weather forecasts are the commodity traders. In a widely disseminated article, Dishneau (1993) wrote:

'At 12:20 p.m. on midsummer weekdays, the din at the Chicago Board of Trade fades as grain traders turn to small television sets scattered about the exchange floor. . 'to watch Tom Skilling's WGN midday forecast of weather for the Chicago area and the Midwest.' If Tom Skilling predicts more rain for the waterlogged Midwest, corn and soybean futures prices may soar.... Traders pay attention to Skilling for several reasons: He comes on when the market is open, his unusually detailed forecasts cover the entire Corn Belt, and his predictions are free.... He also has a reputation for accuracy, earned in 1988 for his early and extensive coverage of a devastating Midwestern drought.' 
Education-Local weather personalities frequently visit schools and then tell about their visits on their programs. Many schools have weather stations that provide statistical data that the local weathercasters use in their programs. These television meteorologists are often the only 'scientists' that many young people see. The Weather Channel has a formal program of education called 'The Weather Classroom,' consisting of programs for teachers to use in the classroom, a 75-page book to supplement the video segments (Moore, 1992), and a quarterly newsletter for educators. The segments are available to teachers to record, and now they sell the series pre-recorded (The Weather Channel, 1997). In all of these educational activities, little attention is given to maps.

It is not uncommon for local stations to provide specials about weather in the area, particularly as tornado and hurricane seasons approach. In Spring 1997, WRTV in Indianapolis had a half-hour special on tornadoes. That presentation contained a segment on how radar images are employed to forecast severe weather and showed examples of how different weather events appear on radar maps. This segment was an unusual educational piece because it instructed about maps and map images.

In general, it is assumed that a viewer interested in weather knows how to read the maps. However, Spiceland (1997) noted that a number of viewers of CNN write in to request that they put the names of the states of the U.S. on the weather maps because the viewers cannot recognize the states in outline form. A number of local weathercasters expressed concern that many viewers are not able to locate themselves on the local maps they use, but they do not know how large that audience is. Sensitive presenters seek a balance between pointing out places on the map as they are mentioned without insulting the intelligence of those viewers who are comfortable with the maps. Some weathercasters take pride in their ability to inject geographic comments while pointing out weather patterns on maps. Loffman (1997b) suggests that meteorologically trained weathercasters would be well advised to add more advanced components to their presentations because he has observed that with the packaged technology there is little difference between the presentations of the well-trained weathercaster and the non-trained person who has on-air charisma. The conscientious weathercaster has an obligation to tell the story of the weather, educate the viewer, and provide the commentary.

As a different type of education, The Weather Channel often uses fairly simple sequences of maps to illustrate the cause and effect of specific meteorological events. Such a series of maps was used to explain the evolution of a Nor'easter that hit New England and dumped a great amount of snow (Figs.19-21). All big weather events get such treatment including major blizzards, hurricanes, a penetration of particularly cold air, heat waves, extensive droughts, or a stagnating front leading to flood producing rains. Maps in these explanatory segments are normally presented in steps as each new component is overlaid on top of the previous map to illustrate the story. For example, the map sequence used to explain the evolution of the Nor' easter consisted of seven applications of icons or names overlaid on the base map as a voice in the background described how each factor added to the mix.

By contrast, weathercasters on The Weather Channel, as well as local channels have employed a variety of map movies to educate viewers about the dynamics of the temperature departures in the Pacific Ocean as the El Nino event of 1997-98 unfolded. This movie data has been available from one or more government sites so channels can pick it up and rebroadcast the maps as movies.
"These television meteorologists are often the only 'scientists' that many young people see."

"... a number of viewers of CNN write in to request that they put the names of the states of the U.S. on the weather maps because the viewers cannot recognize the states in outline form."
"The conscientious weathercaster has an obligation to tell the story of the weather, educate the viewer, and provide the commentary." 
"The maps in television weather are the subject of promotion as well as a medium of advertising."

". . . he was forced to show radar images on every show even on clear days because the station had invested in the hardware and they wanted to show off their investment."

"The scale of weather has gotten down to the local city. . . If the weather doesn't tell the story of what happened on one viewer's cul-de-sac, then that viewer isn't going to be moved."
Some weathercasters are known for the extra explanations in their presentations. Tom Skilling of Chicago's WGN-TV, a so-called super-station available to some 30 million households, is well known for his explanations of meteorological events as well as his use of a great many maps (Figs. 1114). What he chooses to show is in part influenced by what the technology lets him create. Years ago he used a 3D grid suspended over the map surface to explain a dome of high pressure. This grid was viewed from a perspective position and the surface rose and fell with the change in pressure. With a change in technology he lost the capacity to do that presentation, but gained other capabilities (Skilling, 1995). Skilling uses other interesting map presentation to show a spatial interpretation of the probability of precipitation, e.g., $30 \%$ probability of precipitation. He does this with a map of the Chicago urban area broken into a grid of square cells.

Advertising and Promotion - The maps in television weather are the subject of promotion as well as a medium of advertising. On The Weather Channel, and sometimes on $\mathrm{CNN}$, many of the maps carry advertising along the top border of the map or in a sequence immediately following the presentation of the map (Fig. 18). Many of the products so advertised are related to weather conditions and often are seasonal. Cold medicines are likely to be advertised on the maps showing a Pain Index or the incidence of influenza. Makers of allergy relief medicine sponsor maps of allergy occurrence. Tires and coffee advertisements are likely on maps showing travel conditions or even the synoptic conditions. Perhaps the most novel use of maps for advertising are the spots the Weather Channel uses showing weather fans. In one ad, two fellows are sitting in a bar waiting for 'Weekend Weather' to come on. The face of the one hoping for a cool weekend is made up as a map with isotherms and blue tones, while the face of the other who is looking for a warm weekend is covered with isotherms in gold and orange.

Just as the weathercasters take pride in their map products, the stations compete with each other to attract viewers based on their ability to show better maps. As Doppler radar emerged as a new tool early this decade, stations announced that they had Doppler radar and thus viewers would want to watch their news programs. Similarly, when local stations add new systems to help with better graphic displays of maps, they are likely to advertise the technology to attract a larger audience. This need to adapt to graphics technology to remain competitive may have an impact on what is shown on television. Spiceland (1997) related a story from many years ago in which he was forced to show radar images on every show even on clear days because the station had invested in the hardware and they wanted to show off their investment. Bowser $(1997,61)$ suggests this attitude still exists, "There's more weather in newscasts today than there was five years ago, say market watchers. But whether more weather is a response to viewer demand or simply an 'if you've got it, use it' mentality on the part of station executives who OK spending for state-of-the-art weather equipment is open to debate."

It is interesting to look at the directions of the trends in forecasting and presentation of weather. Henson $(1990,129-30)$ quotes Coleman who predicted that because of budget cuts, local stations would drop weather forecasting and let The Weather Channel or a dial-up service provide the forecasts. Almost a decade later, it appears that the local stations are spending the funds to get the latest technology to compete at the local level. Dickson $(1997 a, 74)$ quotes a meteorologist who points out that, "The scale of weather has gotten down to the local city... If the weather doesn't tell the story of what happened on one viewer's cul-de-sac, then that viewer isn't going to be moved." Dickson (1997b) discusses the technology some 
stations have installed to be competitive. While the service bureaus make available NexRad Doppler radar from the federal government, some stations are purchasing their own radar units so that they can have more control over the radar presentations and have more current data because there is a 5 to 6 minute lag time in getting the NexRad images (Dickson $1997 b, 79)$. As detailed digital map databases have become available, they are being incorporated into more detailed weather map systems to compete for viewership.

There are many ways to approach an examination of the uses of weather maps on television. This discussion looks only at the use of maps in the aggregate, plus a few anecdotal stories. MacEachren (1995) has examined the ways individuals interact with maps. Many opportunities exist to learn more about how individuals use the information they get from viewing weather maps on television.

All television weather presentations in the U.S. employ maps as part of their programs. Therefore, every viewing experience must take into account the presence of maps and in most cases, a weathercaster who is interacting with those maps. After studying television weather map use for many years, a classification of viewers of such maps was developed. This typology was sent to a number of weathercasters. Follow-up interviews on the typology were conducted with the weathercasters. In total, weathercasters endorsed the typology, and one even estimated what percentage of his viewers fell into each category. Based on the many interviews, the typology was refined as below.

Meteorology Addicts are viewers who understand the dynamics of weather systems and who look at the maps and loops of cloud and radar imagery to update their mental maps of the status of the atmosphere in the region and across the country. They want to integrate surface conditions with upper air conditions and appreciate maps or images showing jet streams, ridges, troughs, water vapor, and outputs from computer models.

Weather Fans look at the maps and loops of clouds and radar to see trends in temperature, precipitation and the migration of storm systems. These viewers have a general understanding of the role of humidity, fronts and pressure systems but do not have technical knowledge of atmospheric dynamics. They must have a good knowledge of the geography and place names of their region and the nation to be able to relate weather events to the larger areas.

Locals - Show Me types define the viewers who want to see trends in temperature, precipitation and the migration of storm systems in the local area, the potential for severe weather in the near future, and the forecast for the next day or two. These viewers may have a good understanding of the ways weather events interact with local features. To use the maps, they must be able to understand where they are on the local maps.

Locals - Tell Me types want to know what happened locally in the past few hours, current conditions, the potential for severe weather in the near future, and the forecast for the next day or two. They can get their information just as well from radio as from TV. These viewers are not likely to use the maps on TV, perhaps because they do not know where they are on the maps.

Elsewhere'ers want to know what happened, is happening and is forecast to happen in some distant area. These viewers are interested in some distant place, or places, because they will soon travel to that area, they have friends and loved ones in that area about whom they are concerned, or they have a vested interest in what is happening around the country or in some other part of the world. To learn what is happening at the distant
"As detailed digital map databases have become available, they are being incorporated into more detailed weather map systems to compete for viewership."

\section{A TYPOLOGY OF TELEVISION WEATHER MAP VIEWERS}

"They must have a good knowledge of the geography and place names of their region and the nation to be able to relate weather events to the larger areas."
"These viewers are not likely to use the maps on $T V$, perhaps because they do not know where they are on the maps." 
"... they look at the programs to watch the individual perform, i.e., interacting with the many maps and graphs."

"... individuals may fit into more than one type at any given time, or from time to time."

SUMMARY

"If only all of our maps could be seen by such large audiences with such satisfaction."

"Our cartographic literature and our textbooks have little to say about this most pervasive use of maps." locations, they have to read and interpret the maps and loops of imagery. This category does not include those people who are satisfied by seeing a listing of cities showing the predicted high temperature and a single word about precipitation, i.e., Dallas, $85^{\circ} \mathrm{F}$ and cloudy .

Storm Watchers are individuals who, during times of severe weather, choose to look at the weather presentations to watch storm systems evolve, in part as entertainment. This is particularly true of those not in the path of the threatening weather. For many of these viewers, watching a severe weather event unfold on television is comparable to others watching a sporting event on television. The ability to watch weather events progress across the country is facilitated by the 24-hour weather programs, and may be supplemented by the presentations of local weathercasters.

Fans of the Presenter are those many people who see the weathercaster as a friendly and knowledgeable personality and they look at the programs to watch the individual perform, i.e., interacting with the many maps and graphs.

Ho-Hum'ers is the term used to characterize those individuals who have little or no interest in the weather presentation but see the maps and the weathercaster only as the current thing on the screen. For many people, weather, with its many maps, is something that fills the screen until they get to the next part of the program, which is often sports, in the case of local news. Most likely, these people have never seen a full-time weather channel because they have no interest in the subject.

Depending on the desire and motivation of the viewers who can read and understand the maps, individuals may fit into more than one type at any given time, or from time to time. This typology of the viewers of weather maps on television is offered as an organizing theme for further study of the nature of the use of this unique map viewing experience.

Television weather programming in the U.S. provides exposure to maps of many types, even though all are focused on weather related matters. Arguably the greatest map viewing audience is that of the television weather map and the greatest number of maps made day to day are the maps for presentation of weather on television across the country and around the world. It is a big business with large audiences. Besides being a business, it is a means for agencies and individuals to disseminate warnings and give guidelines, a means to transmit helpful advice, and an aid for planning activities. In the process, many people learn some geography and much about the atmospheric sciences. And, it happens in a unique map viewing environment where users can tune in at predictable times and see new information overlaid on a series of base maps with which they have become comfortable, presented by a person they are used to seeing. If only all of our maps could be seen by such large audiences with such satisfaction.

Essentially, cartographers have no input into the production or presentation of weather maps on television. Certainly there are artists and weather presenters who have had some training in cartography but seemingly cartographers are not an important part of television weather mapping. Our cartographic literature and our textbooks have little to say about this most pervasive use of maps.

Although the majority of adults cannot use maps effectively, television weather, with its many maps, is the most popular part of the local news and 24-hour weather channels proliferate. This seems to be a conflicting statement. The typology of viewers of weather maps on television should serve as a foundation to learn more about what viewers want and get from viewing television weather maps. Television weather exists in a unique user 
environment and it may be that the appeal and use of many complementary maps in this supported environment is significantly different from the appeal and use of maps in other environments. This is but one of many questions on this subject that require further study.

American Meteorological Society, 1997, "Seal of Approval Program for Radio and Television," Bulletin of the American Meteorological Society, Vol. 78, No. 8, (August), 1749-52.

AM Weather, 1995, Personal telephone interview with a representative of Maryland Public Television.

Bowser, Andrew, 1997, "Weather Fronts Local News," Broadcasting and Cable Vol. 127, No. 44, (October 27), pp. 61-68.

Brewer, Cynthia A., 1997, "Spectral Schemes: Controversial Color Use of Maps," Cartography and Geographic Information Systems, Vol. 24, No. 4, pp. 203-220.

Brown, A., 1993, "Map Design for Screen Displays," The Cartographic Journal, Vol. 30, pp. 129-135

Carter, James R., 1988, "A Typology of Geographic Information Systems," Technical Papers, 1988 ACSM-ASPRS Annual Convention, Vol. 5, pp. 207-215.

Carter, James R., 1996, “Television Weather Broadcasts: Animated Cartography Aplenty," Proceedings of the Joint International Cartographic Association Commission Seminar on Teaching Animated Cartography, Universidad Politecnica de Madrid, August 30-September 1, 1995, pp. 41-44.

Dickson, Glen, 1997a, "Weather Systems Get Automated," Broadcasting and Cable, Vol. 127, No. 44, (October 27), pp. 74-78.

Dickson, Glen, 1997b, "Getting Up-To-The-Minute With Radar," Broadcasting and Cable, Vol. 127, No. 44, (October 27), p. 79.

Dishneau, David, 1993, "Forecaster has grain trader's ears: Skilling's the word on weather," The Knoxville Newos-Sentinel, (July 6), p. C4.

DR, 1996, "Broadcasting: Survey Says ..." Weatherwise, Vol. 48, No. 2, (April/ May), pp. 11-12.

Eck, Dale, 1997, Personal telephone interview with Dale Eck of The Weather Channel.

Flanagan, Pierce, 1998, Personal telephone interview with Pierce Flanagan of Kavouras Corporation.

Haddad, Charles and Doug Cress, 1993, "Folks at the weather channel just love the rotten weather," The Knoxville News-Sentinel, July 20, 1993, B4.

Henson, Robert, 1990, Television Weathercasting: A History. Jefferson, North Carolina: McFarland \& Company, Inc., $193 \mathrm{pp}$.

Horne, Thomas A., 1992, "The Weather Tube: Meteorology for the flying couch potato", The AOPA Pilot, (November), pp. 93-99. 
Jones, Valerie, 1998, personal telephone interviews with Valerie Jones of Rainbow Raster Graphics, Inc., Knoxville, TN.

Lindgren, Patricia Caldwell, 1991, "Television News Maps and Desert Storm," Bulletin, American Congress on Surveying and Mapping, No. 133, (August), pp. 30-33.

Loffman, Tom, 1997a, "The Weathercaster: Information and Resources for Television \& Radio Weathercasters," as of 8/19/97, URL: http:// www.tloffman.com/wxcaster.htm

Loffman, Tom, 1997b, "The First 100 Tapes," as of 8/19/97, URL: http:// www.tloffman.com/100tapes.txt

MacEachren, Alan, 1995, How Maps Work: Representation, Visualization and Design. New York: The Guilford Press.

Merli, John, 1997, "LIN weathers retrans consent," Broadcasting and Cable Vol. 127, No. 44, (October 27), p. 72.

Mirsky, Steve, 1996, "Turning Weather Wonks into TV Stars," Technology Review, Vol.99, No.8, (November-December), pp.41-45.

Monmonier, Mark, 1996, "Cartographic Complementarity: Objectives, Strategies, and Examples," in C.H. Wood and C.P. Keller, eds., Cartographic Design: Theoretical and Practical Perspectives. Chichester: John Wiley \& Sons, pp. $77-90$.

Monmonier, Mark, 1997, "The Weather Map: Exploiting Electronic Telecommunications to Forecast the Geography of the Atmosphere," in Susan Hanson (ed.), Ten Geographic ldeas That Changed the World. New Brunswick, NJ: Rutgers University Press, pp. 40-59.

Moore, Karen Wenning, 1992, The Weather Classroom, Atlanta: The Weather Channel, Education Services.

Muehrcke, Phillip C., 1996, "The Logic of Map Design," in C.H. Wood and C.P. Keller, eds., Cartographic Design: Theoretical and Practical Perspectives. Chichester: John Wiley \& Sons, pp. 271-278.

National Weather Association, 1997, "Radio \& Television Weathercaster Seal of Approval: Qualifications and Procedures," as of August 3, 1997. http://www.nwas.org/seal.html

Peterson, Michael P., 1995, Interactive and Animated Cartography. Englewood Cliffs, NJ: Prentice Hall.

Petrozzello, Donna, 1997a, "All Weather All the Time From The Weather Channel," Broadcasting and Cable, Vol. 127, No. 44, (October 27), pp. 70-71.

Petrozzello, Donna, 1997b, "AccuWeather Makes Cable System Inroads," Broadcasting and Cable, Vol.127, No. 46, (November 10), p. 70.

Scharfe, Wolfgang (ed.), 1997, Proceedings, International Conference on Mass Media Maps: Approaches, Results, Social Impact. Berliner Geowissenschaftliche Abhandlungen, 1997, Reihe C Kartographie, 16. 
Sealls, Alan, 1994/5, "Adventures in Weathercasting," Weatherwise, Vol. 47, No. 6, (December 94-January 95), pp. 62, 58.

Skilling, Thomas, 1995, Personal telephone interview with Tom Skilling of WGN-TV, Chicago.

Spiceland, Flip, 1997, Personal telephone interview with Flip Spiceland of CNN-TV.

Thedwell, Richard, 1996, Personal telephone interview with Rick Thedwell, LIN Broadcasting, Indianapolis, IN.

The Weather Channel, 1997, "The Weather Channel Education Department UPDATE," quarterly newsletter.

Torguson, Jeffrey, 1997, "User Interface Studies in the Virtual Map Environment," Cartographic Perspectives, Vol. 28, Fall 1997, pp. 29-31.

World Meteorological Organization, 1996, "The Public-Private Partnership in the USA for the Delivery of Weather Services and its Relationship to the International Exchange of Meteorological and Related Data and Products," WMO Bulletin, Vol. 45, No. 1, pp. 39-45. 